\title{
Preface - Climate change: what is at stake?
}

\author{
Michel Rogalski \\ CIRED/EHESS-CNRS, \\ 115 Rue du Cherche-Midi, \\ 75006 Paris, France \\ Email: rogalski.michel@orange.fr
}

\begin{abstract}
The second Earth Summit in Rio will open in 2012. The debate will concern the ability of the world to face its future and the participants will hope to provide answers. Climate change and its challenges will be on the agenda, and recommendations will be advanced and the aim will be to implement them quickly. More than any other area, the climate negotiations have all the ingredients that cause deep divisions in the world and highlight different ways of thinking. The extent of the work needed to change course is huge: it is nothing less than a break with a system of accumulation and techno-economic paradigm that is attached to a commitment to low-carbon societies. However, wanting to involve the poor countries in the world to save the climate now, without meeting their pressing needs for life's essentials, can only lead to stalemate.
\end{abstract}

Keywords: climate negotiations; sustainable development; low carbon society; Kyoto Protocol.

Reference to this paper should be made as follows: Rogalski, M. (2012) 'Preface - Climate change: what is at stake?', Atoms for Peace: An International Journal, Vol. 3, No. 3, pp.173-176.

Biographical notes: Michel Rogalski is an economist and researcher at the CIRED (International Research Center on Environment and Development), linked with CNRS and EHESS (School of Advanced Social Studies) in Paris. He taught at the University of Paris 1 and at the EHESS. He was associated with the Experts Group of United Nations about the Relations between Disarmament and Development, and was a member of the working group on North-South Commission of the General Commissariat of Plan (Paris). He was Scientific Director of the review Mondes en développement (Paris-Bruxelles). $\mathrm{He}$ is Director of the French review Recherches Internationales.

The second Earth Summit will be held in Rio in 2012 under a threefold gathering (Rio+20, Stockholm +40 and Johannesburg+10). The whole planet will question its ability to face the future and will have to provide answers. This is not just a recent concern; it comes from far away, judging by the three original dates shown.

Recent decades have seen the need for sustainable development, which is an unavoidable and essential dimension of key areas of human activity. In reaction to the overly pessimistic view of the Club of Rome at the end of the 1960s, with its concern for the depletion of natural resources and its calls for growth limitation, as well as to the idea that unrestricted growth leads to 'bad development', a trend of thought - ecodevelopment - was established at the UNO Conference in Stockholm in 1972. It was then a question of reconciling the socio-economic and ecological objectives while taking into account the 
combined aim of solidarity with the poorest populations present from the North or the South and the right of future generations to live on a habitable planet. In short, to solve, other than by limiting growth, the latent conflict between savage growth and environmental sustainability.

It took ten years for the United Nations to grasp the problem and order a report. The Brundtland Commission returned its report in 1987 and presented, under the heading Sustainable Development, all the key ideas developed in Stockholm. In order to preserve the planet it proposed to adopt methods of environment friendly production and lifestyles and to avoid generalising on a global scale the wasteful and predatory models - the collateral costs of growth of the West. A major Earth Summit was proposed. It was the Rio Summit in 1992, which validated the double right for both development and a healthy environment, and adopted an action plan in the form of recommendations Agenda 21. A few years before, in 1988, an Intergovernmental Panel on Climate Change (the famous IPCC) had been born, showing the same concerns for future climate.

The world was not the same after the Rio Summit and concern about sustainable development spread worldwide with the desire to reconcile environmental protection, economic efficiency and social equity. The triptych of increased production, greater wealth distribution and preserving the future could not be dismissed without causing tension or opposition. Therefore, the concept of sustainable development was attacked from several sides. Proponents of growth decline only saw in it a smart way to make indefinite economic growth presentable, while the South feared that restrictions could be placed on development for some countries, in particular those less advanced economically.

At the same time, increasing concerns about climate change and its principal causes have slowly moved from scientific circles to public opinion and have led States worldwide to engage in coordinated collective actions (Kyoto Protocol) in order to address what has emerged as a global threat to the continuation of human activity on the planet. Under the action of IPCC, specific knowledge on the mechanism of the greenhouse effect, the nature of its anthropogenic origin and its consequences regarding climate change has been developed. On several occasions, recommendations were put forward insisting on urgent action and the potential cost generated by delays in their implementation.

Today, there is little scientific disagreement on the effect of greenhouse gases and on climate trends. Controversy nevertheless continues on the contribution of human activity to global warming, i.e. on where to fix the cursor between anthropogenic cause and natural causes. The debate also focuses on the efficient regime of international coordination, the criteria and instruments of economic analysis used to allow an equitable participation of all the various nations and the public acceptance of associated costs induced by the necessary measures.

The Copenhagen Summit held at the end of 2009 obtained the promise of engagement of most countries on targets to reduce greenhouse gas emissions, especially from countries hitherto unconstrained and aimed to limit the rise in average temperature to $+2^{\circ} \mathrm{C}$ compared with the pre-industrial era. A year later, the Cancun Summit confirmed these commitments and unanimously welcomed it as a 'step forward'. Cancun was able to resume negotiations because the suggested mechanics came from proposals by each country and aimed at putting them into coherence. The Durban Summit will constitute the last intergovernmental meeting devoted to the climate before the Rio Conference in 2012 (Earth Summit +20) takes the broader point of view. 
More than in other areas, climate negotiations give us all the ingredients of major distortions at work on our planet and ways of thinking about it. The debate crystallises the difficulty of decision-making in the scientific world, while at the same time different temporal horizons are mobilised between action and result. Government action is in chronological telescoping with the rhythm of climate change and the assessment cost of implication/advantages derived is difficult to evaluate on the level of the decision-maker in each country. This opens the door to strategies of the type 'leave the effort to others and let us benefit from its possible effects'.

Very early on, the principle of common but differentiated responsibility was admitted. Therefore, since 1997, developing countries from the South made three major requests during negotiations: to benefit from a moratorium, to receive financial compensation for adapting themselves, and to commit themselves to less ambitious objectives than countries from the North. They underlined the necessity to take into account the place of production as well as the place of consumption of goods in the evaluation of greenhouse gas emissions. They are driven by large emerging countries with strong growth and therefore high emissions (China, India and Brazil), these countries than the North would like to dissociate from the South. To require large emerging countries with $8-10 \%$ growth to reduce their greenhouse gas emissions means nothing else than to stop their development; this is politically inexpressible.

It is advisable to think about a shift towards a massive transfer of technology and knowledge sharing, obliging countries from the North to deviate from the principle of intellectual property in order to gain in energy efficiency to develop renewable energies and to implement a transition towards a low carbon economy, whatever the mechanics in any event under the aegis of the UN - that will carry the global architecture to be built. It will fail if it is viewed as a constraint, rather than a lever as was the IAEA, which succeeded in helping around 40 countries to develop nuclear power without letting those head towards nuclear weapons. It will probably be necessary to shoulder 'bilateral' cooperation, such as the Sino-American one in the field of environment, as long as it moves in the right direction. Without further changes, the Kyoto Protocol must be consolidated. It obviously has to be extended to the countries from the South and to the USA, without necessarily inter-connecting the tradable permit markets. The economic instruments of environmental management are various and complementary: the cap on emissions and tradable permits that accompany them in order to respect the 'non-diffuse' sectors where investors are identifiable and controllable, and taxes for the diffuse sector, involving the consumer and aiming to promote alternative lifestyles. On condition, of course, that we do not consider the planet as an established world economy where the same standards apply indiscriminately without regard to the levels of development and specific trajectories of each country. As Copenhagen taught us, it will still be necessary to learn how to have sovereign coordination and not forget that, in a period of crisis, mobilisation of efforts is more problematic.

Scientific controversy is outdated and should not weigh too much in the debate. However, great danger awaits any substantial advance on the climate. The amount of work needed to change course is immense. This mainly means breaking away from a regime of accumulation and the techno-economic paradigm attached to it and moving on towards low carbon societies. Considerable means will have to be mobilised. Although 
the objectives of the Millennium are far from achieved, how can we imagine that all those suffering the worst affects on the planet will easily accept that these resources be diverted for the benefit of future generations, while the question they face is one of daily survival? To involve them in saving the climate without immediately satisfying their most vital needs could only lead to deadlock. 